\title{
Hypertension in aging: physical activity as primary prevention
}

\author{
D. Ben-Sira • J. M. F. Oliveira
}

Received: 27 June 2007 / Accepted: 27 June 2007 /Published online: 21 July 2007

(C) EGREPA 2007

\begin{abstract}
In most physiologic systems, there is considerable evidence that the normal aging processes do not result in significant impairment or dysfunction in the absence of pathology and under resting conditions. However, in response to a stress, the age-related reduction in physiologic reserves causes a loss of regulatory or homeostatic balance. This happens before an individual notices that something is wrong. An additional consequence of age-related changes is an increased perception of effort associated with submaximal work. Thus, a vicious cycle is set up, leading to decreasing exercise capacity, resulting in an elevated perception of effort, subsequently causing avoidance of activity, and finally feeding back to exacerbation of the agerelated declines secondary to disuse. Sedentary behavior is an important risk factor for chronic disease morbidity and mortality in aging. However, there is a limited amount of information on the type and amount of activity needed to promote optimal health and function in older people [19]. The purpose of this review is to discuss the important role of exercise training as a primary prevention tool to hypertension. In addition, this review will address the topic of the recommended amount of physical activity required for health promotion along with the current exercise guidelines.
\end{abstract}

Keywords Work capacity - Aerobic exercise . Isometric exercise $\cdot$ Sympathetic nerve activity

D. Ben-Sira $(\bowtie)$

Life sciences Department, the Zinman College of Physical Education and Sport Sciences, Wingate 42902, Israel

e-mail: ben-sira@wincol.ac.il

J. M. F. Oliveira

Faculdade de Desporto da Universidade do Porto,

Porto, Portugal

\section{Exercise training and blood pressure}

By the year 2030, the number of individuals 65 years and over will reach 70 million in the USA alone; persons 85 years and older will be the fastest growing segment of the population. As more individuals live longer, it is imperative to determine the extent and mechanisms by which exercise and physical activity can improve health, functional capacity, quality of life, and independence in this population. Aging is a complex process involving many variables (e.g., genetics, lifestyle factors, chronic diseases) that interact with one another, significantly influencing the manner in which we age [1].

Many studies provide evidence that in developed nations such as the USA, a sedentary lifestyle contributes significantly to development of the major risk factors for age-related disease, prominent among them being obesity, diabetes, and hypertension [44]. Conversely, there is increasing evidence that a high level of activity during old age and consequently an influence on the aging process can be achieved by regular training initiated as early as young adulthood. The focus of this training process should be on improving muscle strength, general flexibility, and cardiovascular exercise. Thus, it is appropriate to perceive physical activity as a medical prescription for the aging population [4, 34].

The high prevalence of hypertension in modern industrialized societies imposes a considerable public health problem [35], and therefore, prevention of hypertension is a major public health objective. Hypertension is a serious health problem that increases the risk of coronary heart disease, stroke, and kidney disease [29, 41]. Physical inactivity has been shown to be associated with hypertension in epidemiologic studies [5, 37]; hence, physical activity has been recommended in the prevention and treatment of hypertension $[21,28,30]$. 
A large body of data demonstrates that changes toward a more physically active lifestyle positively affect blood pressure response in normotensive and hypertensive individuals $[8,22,39]$. A meta-analysis of longitudinal aerobic training studies [24], in mild essential hypertensive subjects, demonstrates an average reduction in resting systolic and diastolic blood pressures of 10.8 and $8.2 \mathrm{mmHg}$, respectively [22]. Therefore, participation in an exercise training program can be viewed as a nonpharmacological approach for preventing and treating mild hypertension.

High physical fitness is associated with lower blood pressure in both men and women $[8,16,20]$. Data indicate an association between baseline physical activity fitness and risk of future hypertension. Multiple regression evaluation demonstrated that untrained individual had a $62 \%$ increased risk of developing hypertension compared to their trained peers [6]. Furthermore, this study demonstrates that changing sedentary lifestyle habits to a more active lifestyle is coupled with a reduced risk of becoming hypertensive. Moreover, in a follow-up test the incidence of hypertension in the group who stayed untrained was 32 per 1,000, as compared to only 18 per 1,000 in those who improved their fitness category. Hence, enhanced levels of physical fitness play a significant primary prevention for hypertension $[16,20]$.

The effects of fitness on mortality among hypertensive adults, either from cardiovascular disease or from all causes, are not fully understood, especially among women [20]. The objective of this study was to examine the effect of fitness on all-cause and cardiovascular disease mortality among hypertensive and normotensive women and men. Using the Lipids Research Clinics Prevalence Study, the relationship of fitness with mortality among 2,712 women and 3,000 men followed from 1972-1976 to 1998 were examined. Cardiorespiratory fitness was measured using a treadmill test. Sex-specific hazards were calculated from proportional hazard models of fitness predicting all-cause or cardiovascular disease mortality, adjusted for age, education, race, smoking, alcohol, body mass index, and hyperlipidemic sampling strata. Comparing the lowest with the highest quintile of fitness, the adjusted all-cause mortality among hypertensive women was 1.7 (95\% confidence interval $=0.9-3.2$ ) and among normotensive women was 2.3 (1.5-3.7). Comparing the same quintiles of fitness, the adjusted all-cause mortality among hypertensive men was $2.0(1.2-3.4)$, and among normotensive men, it was $1.9(1.3-2.7)$. Elevated risks were also observed for cardiovascular disease mortality. The authors of this study concluded that higher levels of fitness are associated with a lower risk of all-cause and cardiovascular disease mortality among both hypertensive and normotensive women and men. The relative beneficial impact of physical fitness on blood pressure and all-cause mortality were demonstrated in normotensive and borderline hypertension subjects [7].

Regular practice of exercises, a low-calorie diet, and reduction in sodium intake are well-established nonpharmacological approaches in the nonpharmacological treatment of high blood pressure [36] and are proposed as the first strategy in the treatment of mild or moderate hypertension [15].

Previous studies have shown that a supervised exercise program leads to a decrease in blood pressure in humans with essential arterial hypertension [23, 42]. Men in the high fitness group with resting systolic blood pressure above or equal to $140 \mathrm{mmHg}$ had a lower death rate than men in the low fitness group with resting systolic pressure below $140 \mathrm{mmHg}$. Nevertheless, although the reduction in blood pressure as a result of exercise training is detected in both normal and hypertensive patients, the magnitude of reduction in systolic and diastolic blood pressure at rest and during submaximal exercise is greater in hypertensive subjects $[7,14]$.

Recently, it was suggested that a nonsupervised exercise program followed remotely via the Internet causes a reduction in systolic and diastolic pressures - similar to those observed in supervised physical training programs [36]. That is, the nonsupervised program decreases blood pressure mainly among individuals with higher blood pressure levels. The decrease in blood pressure after a 6-month aerobic physical training program is even more extensive than after a 3-month program. This alteration in blood pressure is independent of body mass index, waist circumference, and body weight loss. Previous studies of supervised exercise programs also show that the reduction in blood pressure may be independent of body weight reduction $[9,14]$.

Evidences accumulated in the past few years show that nonpharmacological management should be the initial strategy to treat overweight individuals with mild to moderate hypertension [2, 46]. A single exercise session is known to decrease blood pressure in hypertensive individuals [10]. This hypotensive effect may continue with the repetition of exercise sessions over time [3, 47]. However, these beneficial effects of exercises are restricted to supervised physical training programs or cardiovascular rehabilitation programs in patients already affected by cardiac events $[12,32]$. Therefore, little is known on the impact of a nonsupervised physical training program on blood pressure.

Aerobic training is not the only form of exercise found to decrease resting blood pressure. Strength training, in the form of circuit weight training, seems to produce the same effect on blood pressure as endurance training. Chronic participation in resistive exercise was once thought to produce elevated resting arterial pressure by causing 
vascular hypertrophy and increased vascular resistance because of large increases in arterial pressure elicited by the isometric or resistive exercise. However, studies have shown that this is not the case. Reductions in arterial pressure have been reported after isometric or resistive exercise training such as isometric handgrip exercise or weightlifting [25, 27, 33, 48].

Furthermore, epidemiological data indicate that regular exposure to high isometric activity at the workplace lowers the incidence of hypertension by as much as $29 \%$ [13]. These limited findings suggest that isometric exercise training may become an important part of a nonpharmacological intervention to prevent and combat hypertension. However, only few studies have examined the effectiveness of purely isometric training on reducing arterial pressure $[25,26]$ Howden et al. [26] documented a reduction of $4.7 \%$ in resting diastolic pressure after 9 weeks of a circuit resistance training program. Likewise, Stewart [44] demonstrated a reduction in mean resting blood pressure from $145 / 97$ at baseline to $131 / 84$ in mild hypertensive patients participating in the circuit weight training group after 10 weeks of training. The magnitude of the reduction is equal to the values observed in the walking/jogging training group.

These studies show that isometric training elicits reductions in mean diastolic and mean arterial blood pressure at rest. Although the reported reduction in diastolic arterial blood pressure appears modest $(2-5 \mathrm{mmHg})$, recent studies indicate that small reductions in diastolic arterial pressure in the population could have significant health benefits. A 2-mmHg drop in diastolic arterial pressure can lead to a $17 \%$ decrease in hypertension as well as a $6 \%$ reduction in coronary heart disease and a $15 \%$ reduction in stroke-related events [17]. A 5- to 6-mmHg reduction in diastolic arterial pressure decreased coronary heart disease and stroke incidents by 16 and $38 \%$, respectively [17]. Thus, the $5-\mathrm{mmHg}$ reduction reported in this study can significantly affect cardiovascular-related illnesses. Furthermore, these results support the concept that isometric training is an effective modality in the prevention of hypertension.

Brandon et al. [11] reported the effects of a 4-month strength training program on strength and blood pressure in older adults. The training protocol for the 43 experimental subjects $($ age $=72.1 \pm 5.5$ years; weight $=72.4 \pm 12.3 \mathrm{~kg}$; body mass index $=26.3 \pm 3.4$ ) consisted of $8-12$ repetitions at each of 50,60 , and $70 \%$ of their one repetition maximum, 3 days a week, for 16 weeks. The results revealed that systolic blood pressure remained unchanged, while mean arterial blood pressure and diastolic blood pressure decreased 2.4 and $3 \mathrm{mmHg}$, respectively. Strength and blood pressure are significantly but moderately related both before and after the training intervention. These results show that moderate intensity strength training greatly improved strength in older adults and had no adverse affect on blood pressure responses.

How does physical activity produce the decrease in blood pressure in elderly and in borderline hypertensive patients? The mechanism(s) responsible for the reduction in arterial pressure has not been investigated. One possible mechanism that may lower arterial pressure as a result of exercise training is a reduction in sympathetic nerve activity. What mechanism could be responsible for the reduction in arterial pressure observed with isometric forearm training? In Ray and Carrasco's study [41], the lack of change in the muscle sympathetic nerve activity after training indicates that the lower arterial pressure is unrelated to a reduction in central sympathetic outflow. The failure of muscle sympathetic nerve activity to change at rest with isometric training is also typically observed with either forearm or leg dynamic exercise training [40, 43]. Therefore, reductions in sympathetic outflow to the skeletal muscle do not appear to be a prerequisite to lower arterial pressure in humans. However, it cannot be excluded that sympathetic outflow to other vascular beds (e.g., visceral regions) may be reduced and may contribute to the reduction in arterial pressure at rest [41].

Another possible mechanism for the reduction in arterial pressure is peripheral vascular adaptations. Because isometric exercise elicits marked increases in muscle sympathetic nerve activity and norepinephrine release, vascular sensitivity to norepinephrine may be decreased with isometric training [31]. Isometric exercise may improve endothelial function. The increased exposure to shear stress on the vessels throughout the entire body by the pressor response during isometric exercise may upregulate the production of nitric oxide synthase and increase the release of endothelium-derived nitric oxide [18, 33, 45]. This is a potentially important effect because essential hypertension is associated with an impairment of endothelium-derived vasodilation related to nitric oxide production [38].

\section{Conclusions}

There is encouraging evidence that moderate levels of physical activity may provide protection from certain chronic diseases. Additionally, substantial health effects can be accrued independent of the fitness effects achieved through sustained vigorous activity. Thus, regular participation (i.e., $30 \mathrm{~min} /$ day on most days of the week) in activities of moderate intensity (such as walking, climbing stairs, biking, or yard work/gardening), which increase accumulated daily energy expenditure and maintain muscular strength, should be encouraged in older adults, even if it is of insufficient intensity for improving fitness. Partic- 
ipation in regular physical activity (both aerobic and strength exercises) elicits a favorable blood pressure response that contribute to healthy aging. Much has been learned recently regarding the adaptability of various biological systems, as well as the ways that regular exercise can influence them. Participation in a regular exercise program is an effective intervention/ modality to reduce/ prevent a number of functional declines associated with aging. Furthermore, the trainability of older individuals is evidenced by their ability to adapt and respond to both endurance and strength training. Endurance training can help maintain and improve various aspects of cardiovascular function (as measured by maximal $\mathrm{VO}_{2}$, cardiac output, and arteriovenous $\mathrm{O}_{2}$ difference), as well as enhance submaximal performance. Importantly, reductions in risk factors associated with disease states (hypertension, heart disease, diabetes, etc.) improve health status and contribute to an increase in life expectancy. It is important to note that while participation in physical activity may not always elicit increases in the traditional markers of physiological performance and fitness (e.g., $\mathrm{VO}_{2} \max$, mitochondrial oxidative capacity, body composition) in older adults, it does improve health (reduction in disease risk factors) and functional capacity. Thus, the benefits associated with regular exercise and physical activity contribute to a more healthy, independent lifestyle, greatly improving the functional capacity and quality of life in this population.

Diastolic arterial pressure appears to be effectively lowered by isometric and resistive training in a large segment of the population. In summary, aerobic and isometric training are effective in lowering arterial pressure in aged normotensive subjects. Isometric training may be an effective nonpharmacological intervention in the prevention and treatment of hypertension. The reduction in arterial pressure is related to changes in muscle sympathetic nerve activity in addition to peripheral vascular adaptations. Notable aspects of aerobic and isometric forearm exercise are that it can be performed quickly, easily, and in any location. These attributes may increase elderly compliance to prescribed training interventions and thereby enhance the probability of positive clinical outcomes.

\section{References}

1. ACSM (1998) Position stand exercise and physical activity for older adults. Med Sci Sports Exerc 30:992-1008

2. Appel LJ (1999) Nonpharmacologic therapies that reduce blood pressure: a fresh perspective. Clin Cardiol 22:1-5

3. Barengo NC, Hu G, Kastarinen M et al (2005) Low physical activity as a predictor for antihypertensive drug treatment in 2564-year-old populations in Eastern and South-western Finland. J Hypertens 23:293-299
4. Bassuk SS, Manson JE (2003) Physical activity and the prevention of cardiovascular disease. Curr Atheroscler Rep 5:299-307

5. Berlin JA, Colditz GA (1990) A meta-analysis of physical activity in the prevention of coronary heart disease. Am J Epidemiol 132:612-628

6. Blair SN, Goodyear NN, Gibbons LW, Cooper KH (1984) Physical fitness and incidence of hypertension in healthy normotensive men and women. JAMA 252:487-490

7. Blair SN, Kohl HW 3rd, Paffenbarger RS Jr, Clark DG, Cooper KH, Gibbons LW (1989) Physical fitness and all-cause mortality. A prospective study of healthy men and women. JAMA 262:2395-2401

8. Blair SN, Kohl HW 3rd, Barlow CE, Gibbons LW (1991) Physical fitness and all-cause mortality in hypertensive men. Ann Med 23:307-312

9. Blumenthal JA, Emery CF, Madden DJ et al (2000) Cardiovascular and behavior effects of aerobic exercise training in healthy older men and women with mild hypertension: effects on cardiovascular, metabolic and hemodinamic functioning. Arch Intern Med 160:1947-1958

10. Brandão-Rondon MUPB, Alves MJNN, Brag AMW et al (2002) Postexercise blood pressure reduction in elderly hypertensive patients. J Am Coll Cardiol 39:676-682

11. Brandon LJ, Sharon BF, Boyette LW (1997) Effects of a fourmonth strength training program on blood pressure in older adults. J Nutr Health Aging 1:98-102

12. Brubaker PH, Rejeski J, Smith MJ et al (2000) A home-based maintenance exercise program after center-based cardiac rehabilitation: effects on blood lipids, body composition, and functional capacity. J Cardiopulm Rehabil 20:50-56

13. Buck C, Donner AP (1985) Isometric occupational exercise and the incidence of hypertension. J Occup Med 27:370-372

14. Cade R, Wagemaker H, Zauner C et al (1984) Effect of aerobic exercise training on patients with systemic arterial hypertension. Am J Med 77:785-790

15. Chobanian AV, Bakris GL, Black HR et al (2003) Seventh Joint National Committee on prevention, detection, evaluation, and treatment of high blood pressure (JNC VII). J Am Med Assoc 289:2560-2572

16. Church TS, Kampert JB, Gibbons LW, Barlow CE, Blair SN (2001) Usefulness of cardiorespiratory fitness as a predictor of allcause and cardiovascular disease mortality in men with systemic hypertension. Am J Cardiol 88:651-656

17. Cook NR, Cohen J, Hebert PR, Taylor JO, Hennekens CH (1995) Implications of small reductions in diastolic blood pressure for primary prevention. Arch Intern Med 155:701-709

18. Delp MD, Laughlin MH (1997) Time course of enhanced endothelium-mediated dilation in aorta of trained rats. Med Sci Sports Exerc 29:1454-1461

19. DiPietro L (2001) Physical activity in aging: changes in patterns and their relationship to health and function. J Gerontol Ser A Biol Sci Med Sci 56:13-22

20. Evenson KR, Stevens J, Thomas R, Cai J (2004) Effect of cardiorespiratory fitness on mortality among hypertensive and normotensive women and men. Epidemiology 15:565572

21. Fletcher GF, Balady G, Blair SN et al (1996) Statement on exercise: benefits and recommendations for physical activity programs for all Americans. A statement for health professionals by the Committee on Exercise and Cardiac Rehabilitation of the Council on Clinical Cardiology, American Heart Association. Circulation 94:857-862

22. Gordon NF, Scott CB, Wilkinson WJ, Duncan JJ, Blair SN (1990) Exercise and mild essential hypertension. Recommendations for adults. Sports Med 10:390-404 Review 
23. Hagberg JM, Park JJ, Brown MD (2000) The role of exercise training in the treatment of hypertension: an update. Sports Med 30:193-206

24. Hamer M, Chida Y (2007) Active commuting and cardiovascular risk: a meta-analysis review. Prev Med (in press)

25. Harris KA, Holly RG (1987) Physiological response to circuit weight training in borderline hypertensive subjects. Med Sci Sports Exerc 19:246-252

26. Howden R, Lightfoot JT, Brown SJ, Swaine IL (2002) The effects of isometric exercise training on resting blood pressure and orthostatic tolerance in humans. Exp Physiol 87:507-515

27. Hurley BF, Hagberg JM, Goldberg AP et al (1988) Resistive training can reduce coronary risk factors without altering $\mathrm{O}_{2 \max }$ or percent body fat. Med Sci Sports Exerc 20:150-154

28. Joint National Committee on Detection, Evaluation, and Treatment of High Blood Pressure (1993) The fifth report of the Joint National Committee on Detection, Evaluation, and Treatment of High Blood Pressure. Arch Intern Med 153:154-183

29. Kannel WB, Sorlie P (1979) Some health benefits of physical activity: the Framingham study. Arch Intern Med 139:857-861

30. Kaplan NM (1991) Long-term effectiveness of nonpharmacological treatment of hypertension. Hypertension 18:I153-I160

31. Kingwell BA, Tran B, Cameron JD, Jennings GL, Dart AM (1996) Enhanced vasodilation to ACh in athletes is associated with lower plasma cholesterol. Am J Physiol Heart Circ Physiol 270:H2008-H2013

32. Kodis J, Smith KM, Arthur HM, Daniels C, Suskin N, Mckelvie RS (2001) Changes in exercise capacity and lipids after clinic versus home-based aerobic training in coronary artery bypass graft surgery patients. J Cardiopulm Rehabil 21:31-36

33. Koller A, Huang A, Sun D, Kaley G (1995) Exercise training augments flow-dependent dilation in rat skeletal muscle arterioles. Role of endothelial nitric oxide and prostaglandins. Circ Res 76:544-550

34. Leach RE (2000) Aging and physical activity. Orthopade 29:936-940

35. Mcmahon S, Rodgers A (1994) Blood pressure, antihypertensive treatment and stroke risk. J Hypertens 12:S5-S14

36. Nunes AP, Santos Rios AC, Gisela Arsa da Cunha GA, Barretto AC, Negrão CE (2006) The effects of nonsupervised exercise program, via internet, on blood pressure and body composition in normotensive and pré-hipertensive individuals. Arq Bras Cardiol 86:289-296

37. Paffenbarger RS Jr, Wing AL, Hyde RT, Jung DL (1983) Physical activity and incidence of hypertension in college alumni. Am J Epidemiol 117:245-257

38. Panza JA, Garcia CE, Kilcoyne CM, Quyyumi AA, Cannon RO III (1995) Impaired endothelium-dependent vasodilation in patients with essential hypertension: evidence that nitric oxide abnormality is not localized to a single signal transduction pathway. Circulation 91:1732-1738

39. Predel HG (2002) An exercise program for the hypertensive patient. Leaving hypertension behind. MMW Fortschr Med 144:34-37 German

40. Ray CA (1999) Sympathetic adaptations to one-legged training. J Appl Physiol 86:1583-1587

41. Ray CA, Carrasco DI (2000) Isometric handgrip training reduces arterial pressure at rest without changes in sympathetic nerve activity. Am J Physiol Heart Circ Physiol 279:H245-H249

42. Rogers MW, Probst MM, Gruber JJ, Berger R, Boone Junior JB (1996) Differential effects of exercise training intensity on blood pressure and cardiovascular responses to stress in borderline hypertensive humans. J Hypertens 14:1369-1375

43. Sinoway L, Shenberger J, Leaman G et al (1996) Forearm training attenuates sympathetic responses to prolonged rhythmic forearm exercise. J Appl Physiol 81:1778-1784

44. Stewart KJ (2005) Physical activity and aging. Ann NY Acad Sci 1055:193-206

45. Sun D, Huang A, Koller A, Kaley G (1998) Adaptation of flowinduced dilation of arterioles to daily exercise. Microvasc Res 56:54-61

46. Viskoper R, Shapira I, Priluck R et al (2003) Nonpharmacologic treatment of resistant hypertensives by device-guided slow breathing exercises. Am J Hyperten 16:484-487

47. Whelton SP, Chin A, Xin X, He J (2002) Effect of aerobic exercise on blood pressure: a meta-analysis of randomized, controlled trials. Annals Intern Med 136:493-503

48. Wiley RL, Dunn CL, Cox RH, Hueppchen NA, Scott MS (1992) Isometric exercise training lowers resting blood pressure. Med Sci Sports Exerc 24:749-754 